\title{
THE RARER ARTHROPATHIES
}

\author{
By F. Dudley HaRT, M.D., F.R.C.P. \\ Westminster Hospital, London
}

Pains referable to muscle, bone or joint may occur in almost all diseases in the medical dictionary; were one to list the causes of arthralgia very few conditions would be left out of the differential diagnosis. It is necessary, therefore, to confine ourselves to those conditions which show definite swelling of joint structures accompanied by some degree of pain or discomfort and some disability. Even so the list is long and only those more likely to be encountered will be considered. The importance of recognizing these rare arthropathies lies not only in the fact that they may need specific therapy but also that misdiagnosed as rheumatoid or osteoarthritis the true diagnosis may be delayed several weeks or months or even occasionally years to the detriment of the patient. It is all too easy in any speciality in medicine to think only in terms of a handful of disease processes common in that speciality and to forget that the whole field of medicine may contribute cases very similar in external features but of quite different aetiology. A list of such arthropathies might include:

(a) Those syndromes which are merely a variant of rheumatoid arthritis and do not need to be consic ered as an entity apart; Felty's syndrome, arthritis mutilans, Still's disease, Sjögren's syndrome.

(b) Those syndromes which, though due to a variety of cifferent causes, are commonly manifestations of rheumatoid arthritis; e.g. Palindromic rheumatism, intermittent hydrarthrosis.

(c) Reiter's (Brodie's) syndrome.

(d) Psoriatic arthropathy.

(e) The disseminated ' collagen' or 'pararheumatic' disorders; disseminated lupus erythematosus, polyarteritis nodosa, scleroderma, dermatomyositis.

(f) Manifestations of a generalized granulomatous disease; e.g. tuberculosis, syphilis, yaws, leprosy, sarcoidosis.

(g) Manifestations of other bacterial infective disorders; undulant fever, enteric fever, meningococcal fever, gonorrhoea.

(h) The neuropathies; Charcot's tabetic joint, syringomyelia. (i) Malignant or submalignant conditions; car- $\vec{\omega}$ cinoma of bronchus, lymphadenoma.

(j) Primary haematological conditions; leu- 3 kaemia, haemophilia and other bleeding conditions, thrombocytopenic purpura.

(k) Allergic conditions; anaphylactoid purpura (Osler-Schönlein), serum sickness.

(l) Vitamin deficiency; scurvy, rickets.

(m) Endocrine disorders; acromegaly.

(n) Drug induced arthropathy; e.g. sulpha drugs, penicillin.

This list is not intended to be comprehensive and does not include bony metastastic disease, osteomyelitis, bursitis, Paget's disease, reflex dystrophy, herpes zoster, the osteochondroses ord host of other disorders which may cause pain bu $\oplus$ rarely a true arthropathy. Only some of the or conditions listed above will be considered.

\section{Palindromic Rheumatism}

This disease was described by Hench and Rosenberg as a specific entity, the essential feature $\mathbb{Q}$ of which was a recurrent swelling of the joints $\overrightarrow{\vec{F}}$ unaccompanied by fever, the joint structures suffering no degenerative or inflammatory change with the passage of time. While Hench and Rosenberg insisted that their cases were not a) variant of rheumatoid arthritis, the majority of such 3 cases seen in this country are in the final analysis $:$ and after the passage of time shown to be examples 3 . of this disorder. Rheumatoid arthritis is a remitting-relapsing disease and this palindromic syndrome when we have seen it has merely been 의 rheumatoid arthritis turned, as it were, off and on, demonstrating the essential reversibility of this disease in its early stages. These patients have in their tissues the ' reversibility factor' operating $O$ perhaps every few days; a patient with swollen $N$ painful joints on Monday may be completely free N from signs and symptoms on Wednesday, only to $\omega$ be affected again the next day. In time the complete restitution to normality fails to occur and rheumatoid arthritis of the established usual type $\stackrel{\Phi}{\oplus}$ slowly develops. We have seen cases where the palindromic phase has lasted 30 years only to 
merge gradually into the pattern of a classical rheumatoid arthritis after this time. While other disorders, for example lymphadenoma and undulant fever, may give a similar picture and while there are reported cases of an apparently specific primary palindromic syndrome those patients we have seen with this disorder have in almost all cases in the course of time been revealed as sufferers from rheumatoid arthritis.

\section{Intermittent Hydrarthrosis}

While many conditions may produce intermittent effusion into joints, as with palindromic rheumatism, most cases in our experience eventually demonstrate other signs of rheumatoid disease, either arthritis or spondylitis, and become classical examples of one or other of these disorders. The knees are the most common joints affected, unilaterally or bilaterally.

A typical history is that of a male patient I have seen who had suffered recurrent swelling of one or both knees for nine years. The swelling was not painful and lasted only several days at a time, but considerable inconvenience was experienced. Skin tests for allergic reactions revealed a reaction to certain dusts, long courses of which given by injection failed to affect the subsequent course of events though every natural remission was hopefully attributed to the latest injection given. Spinal stiffness and pain gradually increased and he was eventually correctly diagnosed as a case of ankylosing spondylitis. In both this disorder and in rheumatoid arthritis such intermittent swelling may precede the classical features by several months or years. Nevertheless, not all cases can be accounted for by these two disorders and a number of other underlying causes are occasionally found, for instance-trauma, tuberculosis or undulant fever. Some patients may suffer also from an associated recurrent iridocyclitis; this again suggests a rheumatoid aetiology, ankylosing spondylitis being more common in this association than rheumatoid arthritis.

\section{Reiter's (Brodie's) Syndrome}

Benjamin Brodie described six patients suffering from polyarthritis, urethritis and conjunctivitis early in the 19th century; I00 years later, in 1916 , Reiter described a single similar case which followed bacillary dysentery. This syndrome has been exciting considerable interest lately as cases come to the fore in war time and the years immediately following; nevertheless, singularly little is generally agreed on in this disorder and the aetiology is still obscure.

Certain features are apparent. The triad may follow infective disease of the lower colon and rectum; Paronen described many cases in the
Finnish Army some 13 days after the onset of flexner dysentery. Many cases but by no means all follow exposure to venereal infection, though the gonococcus is not isolated; in some cases the disorder commences two to four weeks after successful penicillin therapy of a known gonococcal infection. The $\mathrm{L}$ or pleuropneumonia-like organism has been considered by some workers as the possible causative agent but the bulk of evidence is against it Though the male sex is predominantly affected, female cases do occur. The skin condition, keratoderma blenorrhagicum, commonly co-exists, as it does with gonorrhoeal infection. Indeed, in these days of readily-available rapidly-effective antibiotic therapy one wonders if many of these cases of Reiter's syndrome do not follow gonococcal infection immediately treated. The latent interval and the development after a variety of pelvic infections makes it appear to be a non-specific arthropathy fired off by a variety of infections. Nevertheless, on occasion its almost epidermic form suggests a more specific aetiological agent. Ford, in following up a number of cases of gonococcal and non-gonococcal urethritis, found that four developed changes in the sacro-iliac joints after earlier arthritis of the ankles and fee Such cases he considers a variant of ankylosing spondylitis, as did Buckley some years previously It is clear that much work remains to be done if this rather untidy corner in the field of rheumatology.

\section{Psoriatic Arthropathy}

There is still a difference of opinion as to this condition, whether it is merely a variant of rheumatoid arthritis in association with the skin condition or whether it is a separate disease entity. In many cases it appears to be no different from any other case of rheumatoid arthritis, in others it presents a more irregular asymmetrical form with a tendency to involve the terminal interphalangeal joints and thumbs. This involvement of all finger joints, metacarpo-phalangeal, proximal and distal interphalangeal, gives rise to the 'sausage' finger described by Dr. Françon at a meeting of the Heberden Society. Where involvement of the distal joint occurs there is frequently, but not invariably, the tell-tale pitting or more diffuse involvement of the nail in that digit. There is no doubt that the association between psoriasis and a rheumatoid type of arthritis is more common than could be accounted for by mere chance. Wassman (1949) found psoriasis in only 0.43 per cent. of ro,000 medical patients, but in 13.I per cent. of r,000 patients with rheumatoid arthritis; Cecil (1949) found it in 5.6 per cent. of 930 rheumatoid sufferers. Fawcett (1950) has described the radiological features. 


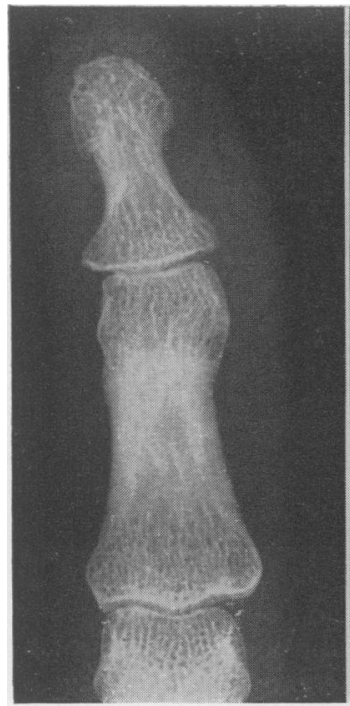

I. $2.5 \mathrm{I}$

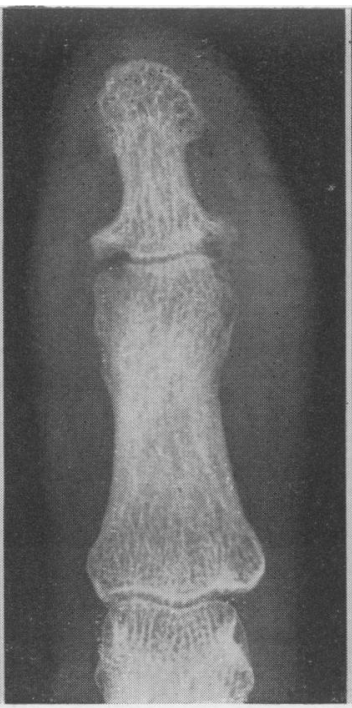

$30.4 \cdot 52$

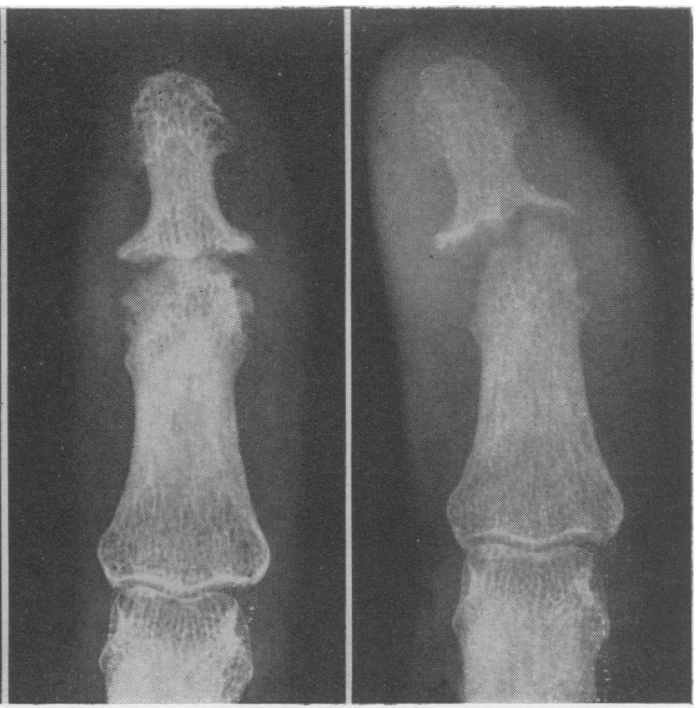

$23 \cdot 9 \cdot 53$
I $4.4 \cdot 54$

Psoriatic arthropathy: progress of a typical lesion in the terminal lesion in the terminal interphalangeal joint of the index finger.

Although there are certain points of difference in psoriatic and rheumatoid arthritis, features common to the two disorders predominate. Until more is known of the aetiology of this whole group of disorders, little is to be gained by dogmatic statements either way.

\section{Disseminated Lupus Erythematosus}

This disorder is much more frequently diagnosed today than it ever was previously. Although the disease may well be more prevalent than before its apparent increase is probably largely due to the fact that the profession has been made more aware of its existence in the last six years. The discovery of the Hargraves or L.E. cell in 1948 helped greatly in correct diagnosis for disseminated lupus erythematosus may present in a variety of ways, one of which is classical rheumatoid arthritis. The condition should always be suspected if an apparent case of rheumatoid arthritis (a) is more ill than arthritic-high fever, for instance, being present with severe systemic upset and only relatively slight physical signs referable to the joints; (b) has the butterfly lilac-red rash over nose and cheeks; (c) has marked abnormality of the plasma protein ratio; (d) has symptoms and/or signs of visceral involvement.

Should any of the above make one suspect disseminated lupus erythematosus a search should be made for the L.E. cell. Th's cell is a polymorphonuclear leucocyte with a large inclusion body consisting of partially depolymerized desoxyribonucleic acid derived from other cells, usually polymorphonuclear but possibly also lymphocytic. It is quite characteristic in appearance and when once seen is readily recognized subsequently.

It is important to re-emphasize that these cases may be apparently classical cases of rheumatoid arthritis, clinically, radiologically and histologically on biopsy. The importance of correct diagnosis lies not only in the therapy instituted but in the much more serious prognosis.

\section{Caplan's Syndrome}

In a study of the X-rays of the lungs of coal miners in a Welsh community Caplan (1953) discovered that there appeared to be an association between a characteristic nodular type of pulmonary fibrosis and rheumatoid arthritis. Miall (1954, 1955) found that the prevalence of rheumatoid arthritis did not differ significantly in miners or non-miners. As progressive massive fibrosis was very common among the miners, over 20 per cent. in the older age group, it seemed unlikely that the fibrosis as such predisposed to rheumatoid arthritis. Pulmonary tuberculosis appeared to be more common in the rheumatoid arthritis group of patients and Miall suggests that the tissue resistance of this group might be different and an inherited altered type of reaction might be responsible for the pulmonary fibrosis in the rheumatoid sufferer. Were this so one might expect to see more examples in other communities, but lung lesions are, on the whole, rare in rheumatoid arthritis. Further statistical information may prove or disprove the significance of the associa- 
tion of what are in any event two very common disorders. At present, though of extreme interest, further information is required before the causal association can be considered proven, but it is of interest that Ball (1955) found the incidence of the differential agglutination test increased in progressive pulmonary fibrosis.

\section{Undulant Fever}

In brucellosis arthralgia is common, arthritis rare, but suppurative or non-suppurative lesions may occur in bone, joint or periosteum. The spine is relatively commonly involved. Joint symptoms are said to be more common in melitensis infections. In brucellosis the large joints are more commonly affected than the small ones, hip for example more than knee, knee more than ankle. Sudden pain with effusion into the joint may occur, the joint becoming tender, hot and swollen but without redness. Transient flitting pains may also occur, simulating rheumatic fever. As noted above true arthritis is rare as compared with arthralgia, true chronic arthritis rarer still. Indeed, some workers (Spink, 1948) found no evidence of a specific chronic arthritis in his series of cases. A similar clinical picture may rarely be given by many other generalized blood stream infections, such as enteric fever, meningococcal fever, smallpox, pneumococcal or staphylococcal septicaemia. The field is well surveyed in the Tenth Rheumatism Review (1953).

\section{Neoplastic Arthropathy}

Hypertrophic pulmonary osteopathy was observed by Hippocrates and was described by Bamberger in 1889 as an ossifying periostitis. Occurring in a variety of conditions, for example carcinoma of bronchus, congenital heart disease, bronchiectasis or chronic lung abscess, it presents no great diagnostic difficulties in most cases. It is not uncommon, however, for a patient with a lung or mediastinal lesion, usually a bronchial carcinoma, to present not only with sub-periosteal proliferation of bone but with synovitis, periarticular swelling and even erosion of articular surfaces. Knees and ankles are more particularly involved and the knees may be greatly swollen with effusion into the joints while arms and hands usually show only coarse thickening of the entire hand and forearm. After removal of the primary lesion the arthropathy may subside rapidly. Such patients with primary lung lesions are commonly sent up to rheumatism units because of the secondary arthritic features, the primary lesion having been overlooked.

\section{Haemophilic Arthritis}

The great majority of haemophilics suffer at some stage of their disease an acute effusion into one or more joints as a result of haemorrhage in the joint cavity or articular structures. Only sligBt trauma is required and the patient may be unaware of having injured the part. The commonest join to be affected are the knee, ankle and elbow, and though no age group is immune in most cases such episodes diminish in frequency as time passes ary the disease lessens in intensity. Haemorrhage info a small joint, such as an interphalangeal articula tion, is more productive of destructive change th when bleeding has occurred into a larger joint, sugh as the knee, where repeated effusions can occiur without leaving any permanent disfiguration $\overrightarrow{o r}$ restriction in range of movement. In some cases, however, synovial proliferation occurs with erosion of the articular cartilage, fibrosis of joint capsule and permanent contraction. A late chief of mine used to teach that if a so-called haemophilic (ov the age of 25) had full range of movement of apI joints, particularly knees, the diagnosis was incorrect. Like most aphorisms, while often true, it is not infrequently quite untrue for in the past year I have seen two cases with full range $\overrightarrow{o f}$ movement of all joints after many episodes off haemarthrosis. In one series of 98 cases कीf haemophilia (Thomas, 1936) arthritis developed 79 per cent. and more than one-half of these casss incurred permanent deformity.

Acute haemarthrosis may occur in any gith bleeding disease, e.g. thrombocytopenic purpmit. The joint affection seen in children with leukaemga s now well recognized.

\section{Acromegaly}

The arthropathy associated with acromegaly his been well described by Kellgren, Ball and Tuttọn (1952). These authors consider that this type off joint disease is a distinct entity. In a few patients they found that massive bony outgrowths interfered with joint movement, giving rise to a clini picture of restriction in articular range. Magre commonly they found striking overgrowth of the articular cartilage and soft tissues with remodelling of the bones which in some cases showed atroplic changes. Softening of ligaments and other structures caused in some cases a curious getatinous or rubbery consistency, with the clinifal picture of limb pains, instability of joints and recurrent synovial effusions. Histological studfss showed no inflammatory changes in the joints but rather a general overgrowth of all the linso structures. The illustrations in this article show well the excessive and abnormal mobility of joints and some of the characteristic radiologfe्al pictures seen in this condition.

\section{Summary}

Only a very light and superficial survey of a $\mathrm{f}_{\mathrm{eg}} \mathrm{W}$ 
of the rarer arthropathies has been attempted in order to emphasize that joint structures may become affected in a very large number of disorders in medicine and surgery, and that in only relatively few of these is the disease primarily of these joint structures. The differential diagnosis of a painful swollen joint or joints takes in a large part of the whole field of medicine; unless one is alive to all the possibilities many underlying primary conditions will be missed.

\section{BIBLIOGRAPHY}

Important references of general interest in each subject are given below:

\section{Palindromic Rheumatism}

HENCH, P. S., and ROSENBERG, E. F. (1944), Arch. int. Med., 73, 293.

ROPES, M. W., and BAUER, W. (1945), New Eng. F. Med., 233, $592,618$.

Intermittent Hydrarthrosis

'Rheumatism Review' (1953), Ann. int. Med., 39, 776.

Reiter's (Brodie's) Syndrome

BRODIE, B. C. (1818, 1836), 'Pathological and Surgical observations on diseases of the joints,' Ist edition, $1818, \mathrm{p}$. $54,4^{\text {th }}$ edition, 1836 , Longman, London.

BUCKLEY, C. W. (1943), Brit. med. F., ii, 4.

FORD, D. K. (1953), Ann. Rheum. Dis., 12, 177.

PARONEN, I. (1948), Acta med. Scand. (Suppl.).

REITER, H. (I9I6), Deutsch. med. Wchnschr., 42, 1535.

Psoriatic Arthropathy

BAUER, W., BENNETT, G. A., and ZELLER, S. W. (I94I), Trans. Ass. Amer. Phys., 56, 349.
CECIL, R. L. (1949), Chicago M. S. and C. Bull., 51, 747.

FAWCETT, J. (1950), Brit. F. Radiol., 23, 440.

'Rheumatism Review' (1953), Ann. int. Med., 39, 767.

SHERMAN, M. S. (1952), $\mathcal{F}$. Bone $\mathcal{F t}$. Surg., 34a, 831 .

WASSMAN, K. (1949), Ann. Rheum. Dis., 8, 70.

Disseminated Lupus Erythematosus
HARGRAVES, M. M., RICHMOND, H., and MORTON, R. (I948), Proc. Staff Meet. Mayo Clinic, 23, 25.

Caplan's Syndrome

BALL, J. (1955), Ann. Rheum. Dis., 14, 159.

CAPLAN, A. (I953), Thorax, 8, 29.

MIALL, W. E. (1954), Quart. F. Med., 23, 465.

MIALL, W. E. (1955), Ann. Rheum. Dis., 14, 150.

Undulant Fever

'Arthritis Review' (1953), Ann. int. Med., 39, 514.

SPINK, W. W. (1948), Ibid., 29, 238.

Neoplastic Arthropathy

BAMBERGER, E. (1889), Wien. Klin. Wschr., 2, 226.

BERG, R. (1949), Dis. of Chest., 16, 483. BERG, R. (1949), Dis. of Chest., 16, 483.
JARVINEN, K. A., and KUMLIN, T. (1954), Ann. Rheum. Dis.,
I3, 52.

THOMAS, C. PRICE (1955), Practitioner, 174, 301.

Haemophilic Arthritis

BOWIE, M. A. ( 1953 ) 'Comroe's Arthritis,' p. 876, 5th edition, edited by J. L. Hollander. Henry Kimpton, London.

COHEN, H. (1954), 'Textbook of Rheumatic Diseases,' p. 281, and edition, edited by W.S. C. Copeman. E. \& S. Livingstone, $-V$ London.

THOMAS, H. B. (1936), f. Bone ft. Surg., 18, 140.

Acromegaly

ATKINSON, F. R. B. (1932), 'Acromegaly,' London.

KELLGREN, J. H., BALL, J., and TUTTON, G. H. (1952), Quart. F. Med., 21, 405. WAINE, H., BENNETT, G. A., and BAUER, W. (1945), Amer
F. med. Sci., 209, 67 I.

\section{PERIPHERAL VASCULAR DISORDERS}

(Postgraduate Medical Journal)

Price: 3s. 8d., post free

THE INVESTIGATION OF PERIPHERAL VASCULAR DISORDERS

Peter Martin, V.R.D., M.Chir., F.R.C.S.(Ed.)

\section{PERIPHERAL ARTERIOGRAPHY AND} AORTOGRAPHY

Robert E. Steiner, M.B., Ch.B., D.M.R., F.F.R., and David Messent, M.B., F.R.C.S.

\section{THE MEDICAL MANAGEMENT OF OBLITERATIVE ARTERIAL DISEASE OF THE LEGS}

Robert Semple, M.D., M.R.C.P.

\author{
RAYNAUD PHENOMENON \\ R. P. Jepson, F.R.C.S.
}

COLLATERAL CIRCULATION IN THE LIMB

C. J. Longland, M.V.O., M.S., F.R.C.S.

\section{SYMPATHECTOMY AND PALLIATIVE OPERATIONS FOR OCCLUSIVE ARTERIAL DISEASE \\ A. J. Slessor, M.V.O., F.R.C.S.}

BLOOD VESSEL GRAFTING

C. G. Rob, M.C., M.Chir., F.R.C.S.

Published by

THE FELLOWSHIP OF POSTGRADUATE MEDICINE

60, Portland Place, London, W.1. 